\title{
(2) OPEN ACCESS \\ COPD discharge bundle and pulmonary rehabilitation referral and uptake following hospitalisation for acute exacerbation of COPD
}

\author{
Ruth E Barker 지 , 1,2,3 Samantha SC Kon, ${ }^{1,3}$ Stuart F Clarke, ${ }^{3}$ Jenni Wenneberg, ${ }^{3}$ \\ Claire M Nolan (1) ,' Suhani Patel, ${ }^{1}$ Jessica A Walsh (ㄷ), ${ }^{1}$ Oliver Polgar (1) ,' \\ Matthew Maddocks, ${ }^{4}$ Morag Farquhar, ${ }^{5}$ Nicholas S Hopkinson ${ }^{10},{ }^{2}$ Derek Bell, ${ }^{6}$ \\ Jadwiga A Wedzicha, ${ }^{2}$ William D-C. Man (1) 1,2
}

- Additional material is

published online only. To view, please visit the journal online (http://dx.doi.org/10.1136/ thoraxjnl-2020-215464).

${ }^{1}$ Harefield Respiratory Research Group, Royal Brompton \& Harefield Hospitals, Guy's and St.Thomas' NHS Foundation Trust, London, UK

${ }^{2}$ National Heart and Lung Institute, Imperial College, London, UK

${ }^{3}$ Hillingdon Integrated Respiratory Service, The Hillingdon Hospitals NHS Foundation Trust, London, UK ${ }^{4}$ Cicely Saunders Institute of Palliative Care, Policy and Rehabilitation, Kings College London, London, UK ${ }^{5}$ School of Health Sciences, University of East Anglia, Norwich, UK

${ }^{6}$ National Institute for Health Research Collaboration for Leadership in Applied Health Research and Care Northwest London, Imperial College London, London, UK

Correspondence to Ruth E Barker, National Heart and Lung Institiute, Imperial College London, London, UK; r.barker18@imperial.ac.uk

Received 4 June 2020 Revised 12 January 2021 Accepted 31 January 2021 Published Online First 2 March 2021

Check for updates

(C) Author(s) (or their employer(s)) 2021. Re-use permitted under CC BY-NC. No commercial re-use. See rights and permissions. Published by BMJ.

To cite: Barker RE, Kon SSC, Clarke SF, et al. Thorax

2021:76:829-831.

\section{ABSTRACT}

Pulmonary rehabilitation (PR) following hospitalisations for acute exacerbation of COPD (AECOPD) is associated with improved exercise capacity and quality of life, and reduced readmissions. However, referral for, and uptake of, post-hospitalisation PR are low. In this prospective cohort study of 291 consecutive hospitalisations for AECOPD, COPD discharge bundles delivered by PR practitioners compared with non-PR practitioners were associated with increased PR referral (60\% vs $12 \%, p<0.001$; adjusted OR: $14.46,95 \% \mathrm{Cl}: 5.28$ to 39.57 ) and uptake ( $40 \%$ vs $32 \%, p=0.001$; adjusted OR: $8.60,95 \% \mathrm{Cl}: 2.51$ to 29.50). Closer integration between hospital and PR services may increase posthospitalisation PR referral and uptake.

\section{INTRODUCTION}

There is an established evidence base supporting the benefits of pulmonary rehabilitation (PR) following hospitalisation for acute exacerbations of COPD (AECOPD), including improved exercise capacity and health-related quality of life, and reduced readmissions and mortality. ${ }^{12}$ However, PR referral and uptake rates are low. Previous data have shown that only $30 \%$ of eligible patients are referred for posthospitalisation PR, with less than 10\% completing a programme. ${ }^{3}$ Barriers to referral and uptake are complex and multi-factorial. ${ }^{4}$

The COPD discharge bundle (a structured package of evidence-based measures which should be delivered to all individuals) was introduced to facilitate implementation of evidence-based care following hospitalisation for an AECOPD and includes offering referral to PR. ${ }^{5}$ However, bundles can be challenging to implement and their impact unclear. $^{67}$

The aim of this study was to determine predictors of referral for and uptake of post-hospitalisation PR. We hypothesised that delivery of a COPD discharge bundle by a PR practitioner would be associated with increased PR referral and uptake.

\section{METHODS}

This prospective cohort study included consecutive hospital episodes for an AECOPD at Hillingdon Hospital, London, UK, from 1 April 2018 to 31 March 2019 and was considered service evaluation by the Health Research Authority. Patients admitted previously during the study period (and therefore already included in the data collection) were excluded.

Patients were classified according to three exposures (no COPD discharge bundle received; COPD discharge bundle received from a current PR practitioner; COPD discharge bundle received from a practitioner with no involvement in $\mathrm{PR}$ ) and followed-up for 4 weeks after hospital discharge. All COPD discharge bundles (online supplemental figure E1) were delivered by a hospital-based multidisciplinary respiratory team with responsibility for early supported discharge, admission avoidance and community respiratory clinics. Two out of six team members were current PR practitioners, defined as someone also employed to deliver PR (assessments and/or supervision of classes) for a minimum 20\% of their job plan. The research team played no involvement in exposure allocation (no randomisation, no influence on care team assignment). The clinical team delivering the bundle were blinded to the study objectives.

The outcomes were referral for PR (defined as a referral received by PR service) and uptake of PR (defined as the proportion of those referred attending a PR assessment) within 4 weeks of hospital discharge.

Covariates were selected a priori as patient or hospital admission variables which have been shown to be predictors of non-referral and nonuptake of post-hospitalisation PR, including age, length of hospital stay and index of multiple deprivation (IMD) (http://imd-by-postcode.opendatacommunities.org/). ${ }^{89}$

The sample size calculations are available in the (online supplemental data). Outcomes were compared between the two COPD discharge bundle exposure groups using independent t-test (or MannWhitney for non-normally distributed data) or $\chi^{2}$ tests. Associations were investigated using logistic regression. Adjusted ORs with 95\% CIs were estimated with $\mathrm{p}$ values $<0.05$ considered significant, with all clinically relevant covariates inputted into the model using the enter method.

\section{RESULTS}

Of 411 hospital episodes screened, 120 were excluded ( 24 were due to the patient being ineligible for PR and 96 as it was a readmission of a 
Table 1 Baseline characteristics of cohort according to COPD discharge bundle exposure status

\begin{tabular}{|c|c|c|c|c|}
\hline Variable & $\begin{array}{l}\text { No bundle received } \\
(n=63)\end{array}$ & $\begin{array}{l}\text { Bundle received from a hospital } \\
\text { practitioner involved in PR delivery } \\
(\mathrm{n}=25)\end{array}$ & $\begin{array}{l}\text { Bundle received from } \\
\text { a hospital practitioner } \\
\text { with no involvement } \\
\text { in } P R \\
(n=203)\end{array}$ & $\begin{array}{l}\text { Between group } \\
\text { comparison for those } \\
\text { who received bundles } \\
\text { ( } p \text { value) }\end{array}$ \\
\hline Age (years) & $72(9)$ & $72(11)$ & $72(9)$ & 0.975 \\
\hline Male (n (\%)) & $29(46)$ & $12(48)$ & $105(52)$ & 0.725 \\
\hline $\mathrm{FEV}_{1} \%$ predicted & $42(26$ to 62$)$ & 41 (30 to 63$)$ & 37 (26 to 48$)$ & 0.131 \\
\hline $\begin{array}{l}\text { Smoking status: } \\
\text { Never / former / current ( } \mathrm{n}(\%))\end{array}$ & $\begin{array}{l}2(3) / 42(67) / \\
18(29)\end{array}$ & $\begin{array}{l}1(4) / 17(68) / \\
7(28)\end{array}$ & $1(1) / 132(65) / 70(34)$ & 0.180 \\
\hline Median (IQR) duration of inpatient stay (days) & 4 (2 to 9$)$ & 3 (2 to 8$)$ & 3 (1 to 6$)$ & 0.438 \\
\hline Review of respiratory specialist within 24 hours (n (\%)) & $44(70)$ & $24(96)$ & $203(100)$ & 0.116 \\
\hline $\begin{array}{l}\text { Non-invasive or invasive ventilation required during } \\
\text { admission }(\mathrm{n}(\%))\end{array}$ & $4(6)$ & $5(20)$ & $23(11)$ & 0.213 \\
\hline
\end{tabular}

Data expressed as mean (SD) or median (IQR) unless otherwise stated; Independent t-test (or Mann-Whitney for non-normally distributed data) or $\chi^{2}$ test was used to compare groups according to involvement in PR delivery of the hospital practitioner delivering the bundle for those who receive bundles.

$\mathrm{FEV}_{1}$, forced expiratory volume in 1 second; $\mathrm{PR}$, pulmonary rehabilitation.

patient already included) (online supplemental figure E2). Baseline demographics of the 291 episodes included in the study were: 145 women, 146 men; 33\% current smokers; age 72 (SD: 9) years, FEV 38 (IQR: 26 to 52) per cent predicted; length of stay 3 (IQR: 2 to 7 ) days. Baseline demographics according to COPD discharge bundle exposure are shown in table 1.

Of the 63 episodes where the COPD discharge bundle was not used, none were referred for PR. Significantly higher referral and uptakes rates were observed for those who received a COPD discharge bundle from a current PR practitioner (referral: 60\% vs $12 \%, \mathrm{p}<0.001$; uptake: $40 \%$ vs $32 \%, \mathrm{p}<0.001)$.

In adjusted multivariate logistic regression, COPD discharge bundle delivered by a current PR practitioner was a predictor of increased PR referral and uptake (table 2), with length of inpatient stay also an independent predictor for PR referral (table 2).

\section{DISCUSSION}

In this prospective cohort study, provision of a COPD discharge bundle was an important factor in determining referral and uptake rates for post-hospitalisation PR. No resulting PR referrals or uptake occurred when a COPD discharge bundle was not delivered to the patient. Our data supports earlier observations that the introduction of COPD discharge bundles can generate increased referrals for post-hospitalisation PR. ${ }^{10}$

A novel aspect of our study examined whether the role of the practitioner delivering the bundle is influential. Intriguingly, we demonstrated that referral rates were significantly increased when the practitioner delivering the bundle also had responsibilities for delivering PR. Although this could simply represent referrer bias, we were reassured to also observe a higher PR uptake rate in those patients referred by current PR practitioners. After multivariate analysis, taking into account potential confounders such as patient demographics and hospital admission factors, the practitioner's current involvement in delivering PR remained an independent predictor for both increased PR referral and uptake (table 2). We did not collect data on patient face-to-face exposure time with healthcare professionals but there was no difference between the COPD bundle groups in the proportion receiving specialist respiratory review within 24 hours of admission (table 1). Furthermore, respiratory outpatient review took place at 6 weeks post-discharge, and therefore did not influence the primary outcomes (uptake and referral within 28 days of discharge).

One explanation for our observation includes increased referrer knowledge about local referral pathways and processes. Referrer knowledge and attitudes may also influence the

Table 2 Multivariate logistic regression for predictors of PR referral and uptake within 28 days of hospital discharge for those with completed bundles

\begin{tabular}{|c|c|c|c|c|c|c|}
\hline \multirow[b]{3}{*}{ Variable } & \multicolumn{3}{|c|}{ PR referral within 28 day of hospital discharge } & \multicolumn{3}{|c|}{$\begin{array}{l}\text { PR uptake within } 28 \text { days of hospital } \\
\text { discharge }\end{array}$} \\
\hline & \multicolumn{3}{|c|}{ Adjusted multivariate } & \multicolumn{3}{|c|}{ Adjusted multivariate } \\
\hline & OR & $95 \% \mathrm{Cl}$ & $P$ value & OR & $95 \% \mathrm{Cl}$ & $P$ value \\
\hline $\begin{array}{l}\text { Practitioner delivering bundle involved in PR delivery (ref: not involved in } \\
\text { PR delivery) }\end{array}$ & 14.46 & 5.28 to 39.57 & $<0.001$ & 8.60 & 2.51 to 29.50 & 0.001 \\
\hline Age (years) & 0.98 & 0.94 to 1.02 & 0.277 & 0.99 & 0.99 to 1.05 & 0.717 \\
\hline Gender (ref: male) & 0.56 & 0.25 to 1.24 & 0.152 & 1.83 & 0.54 to 6.19 & 0.325 \\
\hline Smoking status (ref: current) & 0.87 & 0.37 to 2.06 & 0.748 & 0.93 & 0.24 to 3.65 & 0.917 \\
\hline Index of multiple deprivation & 1.00 & 1.00 to 1.00 & 0.481 & 1.00 & 1.00 to 1.00 & 0.227 \\
\hline Non-invasive or invasive ventilation required (ref: no) & 1.31 & 0.36 to 4.72 & 0.680 & 1.53 & 0.23 to 3.64 & 0.917 \\
\hline Duration of inpatient stay (days) & 0.89 & 0.80 to 0.99 & 0.037 & 0.88 & 0.72 to 1.03 & 0.178 \\
\hline
\end{tabular}

PR uptake within 28 days of hospital

$P$ value significance $=\leq 0.05$ (in bold); all variables were entered in the model using the enter method

.PR, pulmonary rehabilitation.; 
patient-referrer interaction, which in turn shape the patient's understanding and demystify their expectations of PR. Knowledge is frequently identified as a barrier/enabler for PR referral and participation. ${ }^{11}$ We propose that further research is needed to test whether improving referrer knowledge and experience, perhaps through formal training or closer integration between hospital and PR practitioners, can increase referral and uptake for post-hospitalisation PR. This is particularly important given the paucity of effective interventions that address this area. ${ }^{9}$

A limitation was that this was a single-centre study with small number of practitioners involved, and therefore our results may not be generalisable. However, our results seem mechanistically plausible, and we are confident about the accuracy of the exposure data as the recruiting hospital was financially incentivised to keep rigorous audit records around bundle completion. Furthermore, as the recruiting hospital was served by a single PR service, collection of PR outcome data was simplified. Another limitation is that our study used routinely collected data as part of service evaluation and audit. It is possible that our findings could be explained by confounding factors not collected in our data set, with differences in patient knowledge, beliefs and attitudes between the exposure groups potentially relevant. ${ }^{11}$

In summary, we have demonstrated that COPD discharge bundles are associated with increased referral and uptake rates for post-hospitalisation PR. In particular, COPD discharge bundle delivered by a practitioner delivering PR within their workplan is an independent predictor of PR referral and uptake. Closer integration between clinical services could increase posthospitalisation PR referral and uptake.

Twitter Claire M Nolan @clairemnolan84, Suhani Patel @suhani_patel1, Nicholas S Hopkinson@COPDdoc and William D-C. Man @toplungdoc

Acknowledgements We would like to express our gratitude to the patients for participating in this study. We would also like to thank the staff of the Hillingdon Integrated Respiratory Service for their support with data collection.

Contributors Concept and design of Study: REB, MM, MF, JAW, WM; Acquisition of Data: REB, SSCK, SFC, WM; Analysis of Data: REB and WM; Interpretation of Data: All authors; Drafting and revisions of Manuscript: All authors; Final approval of Manuscript: All authors; Guarantor:WM.

Funding This paper presents independent research funded by the National Institute for Health Research (NIHR) under its Clinical Doctoral Fellowship Programme (Fellowship Reference Number ICA-CDRF-2017-03-018). The funder had no role in the collection, analysis and interpretation of the data; the funder had no role in the writing of and decision to publish this report. The views expressed are those of the author(s) and not necessarily those of the NIHR or the Department of Health and Social Care. REB is funded by a NIHR Clinical Doctoral Research Fellowship (ICA-CDRF-2017-03-018); CMN was funded by a NIHR Doctoral Research Fellowship (DRF-2014-07-089) and a NIHR Clinical Trials Fellowship (CTF-2017-06-005); MM is funded by a NIHR Career Development Fellowship (CDF-2017-10-009) and NIHR Applied Research Collaboration South London; MF is currently part-funded by the $\mathrm{NIHR}$ Applied Research Collaboration East of England programme.

Competing interests REB, SSCK, SFC, JW, CMN, SEJ, SP, JAW, MM, MF and NSH have no competing interests to report. WM reports personal fees from Jazz Pharmaceuticals, personal fees from Mundipharma, personal fees from Novartis, grants from Pfizer, non-financial support from GSK, grants from National Institute for Health Research, grants from British Lung Foundation, outside the submitted work.

Patient consent for publication Not required.

Provenance and peer review Not commissioned; externally peer reviewed.

Supplemental material This content has been supplied by the author(s). It has not been vetted by BMJ Publishing Group Limited (BMJ) and may not have been peer-reviewed. Any opinions or recommendations discussed are solely those of the author(s) and are not endorsed by BMJ. BMJ disclaims all liability and responsibility arising from any reliance placed on the content. Where the content includes any translated material, BMJ does not warrant the accuracy and reliability of the translations (including but not limited to local regulations, clinical guidelines, terminology, drug names and drug dosages), and is not responsible for any error and/or omissions arising from translation and adaptation or otherwise.

Open access This is an open access article distributed in accordance with the Creative Commons Attribution Non Commercial (CC BY-NC 4.0) license, which permits others to distribute, remix, adapt, build upon this work non-commercially, and license their derivative works on different terms, provided the original work is properly cited, appropriate credit is given, any changes made indicated, and the use is non-commercial. See: http://creativecommons.org/licenses/by-nc/4.0/.

\section{ORCID iDs}

Ruth E Barker http://orcid.org/0000-0002-7022-0194

Claire M Nolan http://orcid.org/0000-0001-9067-599X

Jessica A Walsh http://orcid.org/0000-0002-9103-3945

Oliver Polgar http://orcid.org/0000-0002-1320-2096

Nicholas S Hopkinson http://orcid.org/0000-0003-3235-0454

William D-C. Man http://orcid.org/0000-0002-3782-659X

\section{REFERENCES}

1 Puhan MA, Gimeno-Santos E, Cates CJ, et al. Pulmonary rehabilitation following exacerbations of chronic obstructive pulmonary disease. Cochrane Database Syst Rev 2016;12:CD005305.

2 Lindenauer PK, Stefan MS, Pekow PS, et al. Association between initiation of pulmonary rehabilitation after hospitalization for COPD and 1-year survival among Medicare beneficiaries. JAMA 2020;323:1813-23.

3 Jones SE, Green SA, Clark AL, et al. Pulmonary rehabilitation following hospitalisation for acute exacerbation of COPD: referrals, uptake and adherence. Thorax 2014:69:181-2.

4 Jones SE, Barker RE, Nolan CM, et al. Pulmonary rehabilitation in patients with an acute exacerbation of chronic obstructive pulmonary disease. J Thorac Dis 2018;10:S1390-9.

5 Hopkinson NS, Englebretsen C, Cooley N, et al. Designing and implementing a COPD discharge care bundle. Thorax 2012;67:A108

6 Man WD-C, Barker R, Maddocks M, et al. Outcomes from hospitalised acute exacerbations of COPD: a bundle of optimism? Thorax 2017:72:8-9.

7 Ospina M, Mrklas K, Deuchar L. A systematic review of the effectiveness of discharge care bundles for patients with chronic obstructive pulmonary disease. Thorax 2017;72:31-9

8 Steiner MC, Lowe D, Beckford K, et al. Socioeconomic deprivation and the outcome of pulmonary rehabilitation in England and Wales. Thorax 2017;72:530-7.

9 Barker RE, Jones SE, Banya W. The effects of a video intervention on PostHospitalization pulmonary rehabilitation uptake: a randomized controlled trial. Am J Respir Crit Care Med 2020

10 Sewell L, Schreder S, Steiner M, et al. A strategy to implement a chronic obstructive pulmonary disease discharge care bundle on a large scale. Future Healthc J 2017:4:198-201.

11 Cox NS, Oliveira CC, Lahham A, et al. Pulmonary rehabilitation referral and participation are commonly influenced by environment, knowledge, and beliefs about consequences: a systematic review using the theoretical domains framework. J Physiother 2017;63:84-93. 